DOI: https://doi.org/10.24127/ajpm.v10i2.3535

\title{
PENGEMBANGAN SOAL MATEMATIKA TIPE PISA LEVEL 5 DENGAN KONTEKS PRIBADI
}

\author{
Tria Gustiningsi ${ }^{1}$, Somakim ${ }^{2 *}$ \\ ${ }^{1}$ Universitas Sjakhyakirti, Palembang, Indonesia \\ $2^{2 *}$ Universitas Sriwijaya, Palembang, Indonesia \\ * Corresponding author. Perumahan Pondok Indah Residence B-6.30151, Palembang, Indonesia \\ E-mail: $\quad$ triagustiningsi08@gmail.com $\left.{ }^{1}\right)$ \\ somakim_math@yahoo.com ${ }^{2 *}$
}

Received 05 February 2021; Received in revised form 28 June 2021; Accepted 01 July 2021

\begin{abstract}
Abstrak
Penelitian ini bertujuan untuk menghasilkan soal matematika tipe PISA level 5 dengan konteks pribadi yang valid, praktis, dan efektif. Metode penelitian ini adalah design research dengan tipe development studies. Penelitian dilakukan dengan tahapan yang terdiri dari preliminary, self evaluation, expert review, one to one, small group, dan field test. Subjek penelitian adalah 12 orang siswa kelas VII SMPN 1 Palembang. Data dikumpulkan dengan menggunakan walk-through, tes, angket, dan wawancara. Penelitian menghasilkan soal matematika tipe PISA level 5 konteks pribadi yang valid dari segi konten yaitu soal sudah sesuai dengan karakteristik soal PISA level 5 dan sesuai dengan karakteristik konteks pribadi, soal juga sudah valid dari segi konstruk yang terlihat bahwa soal sudah sesuai dengan kurikulum 2013 kelas VII, dan soal sudah valid dari segi bahasa yaitu soal sudah sesuai dengan PUEBI dan tidak menimbulkan penafsiran ganda. Soal yang dihasilkan sudah praktis yaitu soal dapat dipakai, maksud soal dimengerti oleh siswa, dan siswa tertarik mengerjakan soal. Soal yang dihasilkan juga sudah efektif yaitu soal memunculkan keterampilan berpikir siswa. Temuan dari penelitian ini adalah soal yang dihasilkan memiliki efek potensial yaitu memunculkan kemampuan siswa dalam menganalisis, mengevaluasi, dan mencipta.
\end{abstract}

Kata kunci: Konteks pribadi; level 5; soal PISA.

\begin{abstract}
This study aims to produce PISA-like mathematics problems level 5 with a personal context which valid, practical, and effective. This research method is design research with the type of development studies. The study was conducted in stage which consist of preliminary, self-evaluation, expert-review, one-toone, small-group, and field test. The research subjects were seventh graders' of SMPN 1 Palembang. Data were collected using walk-through, tests, questionnaires, and interviews. The result of this study is the product were valid in terms of content, namely the problems were accordance with characteristics of the level 5 in PISA and in accordance with the characteristics of the personal context, the problems were also valid in terms of the construct which showed that the problems were in accordance with the curriculum, and the problems are valid in terms of language, namely the problems are in accordance with the PUEBI and do not cause multiple interpretations. The problems are also practical, namely the problems can be used, the meaning of the questions is understood by students, and student interested to solve the problems. The problems have also been effective, namely raising thinking skills. The findings of this study are that the questions have the potential effect of raising students' ability to analyze, evaluate, and create.
\end{abstract}

Keywords: Level 5; personal context; PISA problem. 
DOI: https://doi.org/10.24127/ajpm.v10i2.3535

\section{PENDAHULUAN}

Kemdikbud (2017) menyebutkan bahwa terdapat beberapa perubahan dalam kurikulum 2013, salah satunya yaitu pada standar penilaian. Penilaian diharapkan dapat membantu siswa untuk meningkatkan keterampilan berpikir tingkat tinggi atau Higher Order Thinking Skill (HOTS), karena jika siswa memiliki HOTS maka siswa dapat berpikir secara luas dan dapat memahami materi pelajaran dengan mendalam. Begitu pula Widodo \& Kadarwati (2013) mengungkapkan bahwa dengan HOTS siswa dapat memahami konsep lebih baik dan pengetahuan siswa luas. Selain itu, HOTS termasuk dalam tingkatan proses kognitif paling tinggi dalam taksonomi bloom yaitu pada tingkat menganalisis (analyzing), mengevalua-si (evaluating), dan mengkreasi (creating) (Effendi, 2017). Hal ini menunjukkan bahwa HOTS sangat penting dimiliki oleh siswa.

Menurut Setiawan, Dafik, \& Lestari (2014)), ada keterkaitan antara HOTS dengan soal Programme for International Student Assessment (PISA) yaitu pada soal PISA terdapat soal level 4, 5, dan 6 yang merupakan level HOTS sesuai taksonomi bloom. Berdasarkan penelitian Oktiningrum (2016), soal PISA memiliki efek potensial memunculkan kemampuan matematika siswa meliputi kemampuan matematisasi, komunikasi, representasi, pemecahan masalah, berargumentasi, dan penggunaan simbol matematika. Sesuai dengan OECD (2019b), salah satu keistimewaan PISA adalah saat siswa memecahkan permasalahan dari soal yang diberikan maka siswa dilatih untuk menerapkan pengetahuan yang sudah dimiliki, menganalisis masalah, bernalar mencari solusi, dan mengomunikasikan dengan efektif
Berdasarkan hasil PISA (Programme for International Student Assessment) menunjukkan bahwa kemampuan siswa Indonesia masih rendah. Pada tahun 2015, dalam bidang matematika Indonesia menduduki peringkat 63 dari 70 negara (OECD, 2016). Pada tahun 2018, dalam bidang matematika Indonesia mendapat peringkat 72 dari 78 negara (OECD, 2019a).

Gustiningsi \& Utari (2020) menyatakan bahwa rendahnya kemampuan berpikir tingkat tinggi siswa berkaitan dengan jenis soal yang diberikan kepada siswa selama ini. Munayati et al (2015) menunjukkan bahwa soal-soal dalam buku teks matematika hanya $46,8 \%$ yang sesuai dengan framework PISA dan tingkat kesulitan soal hanya pada level 4 , tidak ditemukan soal dengan level 5 dan 6 . Fauziyyah (2020) menyatakan bahwa pada buku matematika kurikulum 2013 edisi revisi 2017, soal terbanyak adalah soal level $\mathrm{C}_{3}$ yaitu $28,76 \%$ dan soal paling sedikit yaitu soal level $\mathrm{C}_{5}$ dan $\mathrm{C}_{6}$ yaitu sebesar $0,27 \%$. Hal ini berarti soal level tinggi belum cukup tersedia untuk memfasilitasi siswa. Oleh karena itu, perlu dikembangkan soal-soal tipe PISA level tinggi sebagai perbendaharaan soal dalam pembelajaran matematika.

Konteks dalam PISA terdiri dari konteks pribadi, pekerjaan, umum, dan ilmiah (Johar, 2012). Pada penelitian sebelumnya, Gustiningsi (2015) mengembangkan soal PISA level 4 dengan konteks umum dan menghasilkan soal yang valid dan praktis. Putra, Zulkardi, \& Hartono (2016) mengembangkan soal level 4,5,6 dengan konteks umum yaitu Kota Lampung. 
DOI: https://doi.org/10.24127/ajpm.v10i2.3535

Menurut Baka, Laksana, \& Dhiu (2019), belajar itu harus dimulai dari yang paling dekat dengan siswa. Oleh karena itu penelitian ini mengembangkan soal matematika model PISA level 5 dengan konteks pribadi. Tujuan penelitian ini yaitu menghasilkan soal matematika model PISA level 5 dengan konteks pribadi yang valid, praktis, dan efektif.

\section{METODE PENELITIAN}

Metode dalam penelitian ini adalah metode penelitian design research dengan tipe development studies (Bakker, 2019). Subjek penelitian adalah siswa kelas VII SMPN 1 Palembang berjumlah 12 orang. Tahapan yang dilakukan adalah tahap preliminary dan tahap prototyping (Tessmer, 1993) seperti pada gambar 1.

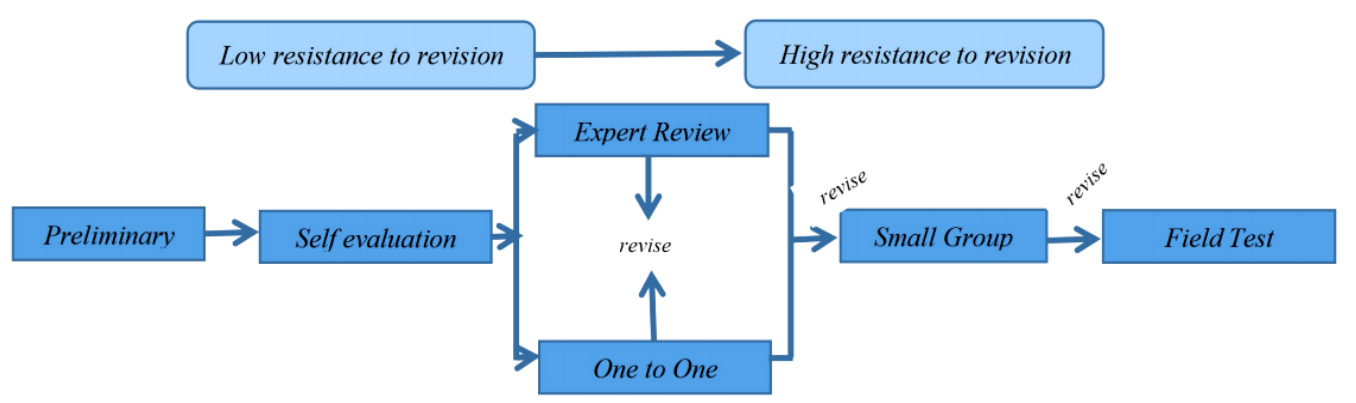

Gambar 1. Alur formative evaluation (Tessmer, 1993; Zulkardi, 2002)

Pada tahap preliminary, dilakukan persiapan untuk mengem-bangkan soal matematika model PISA level 5 konteks pribadi seperti menganalisis materi, menganalisis subjek penelitian, dan menganalisis framework PISA. Selanjutnya tahap prototyping terdiri dari self-evaluation, expert review, oneto-one, small-group, dan field-test

Pada tahap self evaluation, soal matematika tipe PISA dibuat dan disesuaikan dengan framework PISA, dan dievaluasi sendiri sebelum ke tahap selanjutnya. Soal yang telah disusun ini disebut prototype I. Selanjutnya, prototype $I$ divalidasi ke tahap berikutnya yaitu tahap expert review dan one-to-one.

Pada tahap expert-review, prototype I divalidasi oleh 2 orang expert atau pakar di bidang PISA untuk melihat kevalidan soal dari segi konten, konstruk, dan bahasa. Pada tahap oneto-one, prototype I diujicobakan kepada 2 orang teman sejawat untuk mendapatkan saran dan komentar dari segi konten, konstruk, dan bahasa, dan protoype I pada tahap one-to-one juga diujicobakan kepada 5 orang siswa yang bukan subjek penelitian untuk melihat keterpakaian soal yang dikerjakan, dilihat dari jawaban siswa dan komentar siswa pada wawancara saat mengerjakan soal dan pada angket setelah mengerjakan soal. Kemudian, prototype I dianalisis dan direvisi sesuai saran dari expert, teman sejawat, dan sesuai komentar dan jawaban siswa. Soal yang telah direvisi disebut prototype II.

Kemudian, protoype II diujicobakan pada tahap small-group kepada 6 orang siswa yang bukan subjek penelitian. Tahap small-group juga untuk melihat kepraktisan soal yang dilihat dari jawaban dan komentar siswa saat dan setelah mengerjakan soal. Selanjutnya, soal yang telah diujicobakan dianalisis dan direvisi dan selanjutnya disebut prototype III. 
DOI: https://doi.org/10.24127/ajpm.v10i2.3535

Selanjutnya, prototype III diujicobakan pada tahap field-test kepada 12 orang siswa yang merupakan subjek penelitian. Hasil jawaban siswa pada tahap field-test dianalisis dan dilihat efek potensial dari soal yang dikembangkan.

Deskripsi skala kemampuan matematika level 5 yaitu siswa dapat mengembangkan dan bekerja dengan model dan situasi kompleks, dapat mengidentifikasi kendala serta menetapkan asumsi, dapat memilih, membandingkan, dan mengevaluasi strategi pemecahan masalah yang sesuai untuk menyelesaikan masalah kompleks yang terkait dengan model, apat bekerja secara strategis menggunakan keterampilan berpikir dan penalaran, representasi terkait yang sesuai, karakterisasi formal dan simbol, dan wawasan yang berkaitan dengan situasi, serta dapat merefleksikan tindakan dan merumuskan serta mengkomunikasikan interpretasi dan penalaran (OECD, 2013). Masalah atau soal yang termasuk dalam konteks pribadi dalam PISA mencakup pada aktivitas diri sendiri, keluarga, atau kelompok sebaya, dan salah satu kegiatannya yaitu permainan (OECD, 2018).

Data dikumpulkan dengan menggunakan walk-through, tes, angket, dan wawancara. Walk-through digunakan pada tahap expert-review untuk meminta saran dan komentar dari expert, sedangkan tes, angket, dan wawancara digunakan pada tahap oneto-one, small group, dan juga field test. Tes digunakan untuk melihat keterpakaian soal yang dikembangkan (prototype) dan melihat cara berpikir siswa, sedangkan angket dan wawancara digunakan untuk mengetahui komentar, kendala, kesulitan, dan menggali cara berpikir siswa saat mengerjakan soal.
Walk-through dianalisis dengan cara deskriptif, komentar dan saran dari pakar dideskripsikan dan dijadikan bahan untuk merevisi prototype I. Tes dianalisis berdasarkan rubrik penskoran. Hasil tes pada tahap one-to-one dan small-group digunakan untuk merevisi atau mempertimbangkan soal yang dikembangkan, sedangkan hasil tes pada tahap field-test digunakan untuk mengetahui efek potensial dari soal yang dikembangkan. Wawancara dan angket dianalisis secara deskriptif, kemudian digunakan sebagai informasi pendukung dalam proses pengembangan.

Kevalidan soal dari segi konten, konstruk, dan bahasa dilihat pada tahap expert review dan one-to-one pada teman sejawat. Soal dikatakan valid dari segi konten jika soal yang dikembangkan sudah sesuai dengan framework PISA, sesuai dengan karakteristik soal PISA level 5 dan sesuai dengan karakteristik konteks pribadi. Sedangkan, soal dikatakan valid dari segi konstruk jika soal sesuai dengan kurikulum 2013, dan soal dikatakan valid dari segi bahasa jika soal sesuai dengan pedoman umum ejaan bahasa Indonesia (PUEBI) dan tidak multi tafsir. Kepraktisan soal dilihat ketika tahap one-to-one pada siswa dan small group. Soal dikatakan praktis jika soal yang dikembangkan bisa dimengerti oleh siswa, tidak multi tafsir, dan siswa tertarik mengerjakannya. Kemudian kefektifan soal dilihat dari field test yaitu jika soal memiliki efek potensial. Efek potensial dilihat dari jawaban siswa pada saat field-test dan dianalisis berdasarkan taksonomi bloom level C4 (menganalisis), C5 (mengevaluasi), dan C6 (mencipta) (Kemdikbud, 2017). 
DOI: https://doi.org/10.24127/ajpm.v10i2.3535

\section{HASIL DAN PEMBAHASAN}

Pengembangan soal matematika model PISA level 5 dengan konteks pribadi dilaksanakan dengan dua tahap.

1. Tahap Preliminary

Persiapan dilakukan dengan menganalisis kurikulum, menentukan materi soal yang dikembangkan, dan menganalisis framework PISA.

\section{Tahap Prototyping}

Tahap Prototyping dimulai dari tahap self-evaluation yaitu peneliti menyusun soal model PISA sesuai dengan framework PISA, menyesuaikan dengan kriteria level 5 dan konteks pribadi dalam PISA. Soal yang sudah disusun pada tahap ini disebut prototype I. Salah satu soal yang dikembangkan tersedia pada Gambar 2.

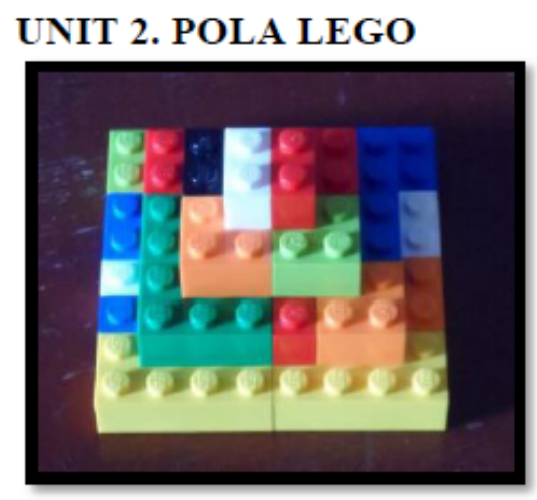

Seorang siswa sedang belajar matematika dengan menggunakan lego. Siswa tersebut membentuk lego menjadi bentuk piramida seperti pada gambar.

\section{Pertanyaan 2:}

Bagaimana strategi yang paling mudah menurutmu untuk mengetahui jumlah bulatan lego pada tingkat ketujuh? Tuliskan strategimu.

\section{Gambar 2. Prototype I}

Berdasarkan Gambar 2, disusun soal atau prototype $I$ yang memenuhi karakteristik kemampuan level 5 antara lain: 1) soal dirancang agar siswa dapat memodelkan dan bekerja dari model tersebut, terlihat dari soal yang dibuat dengan menampilkan foto "lego" yang disusun bertingkat dan menanyakan jumlah bulatan lego pada tingat ke tujuh, 2) soal dirancang agar siswa memilih, membandingkan, atau mengevaluasi strategi, terlihat dari pertanyaan "bagaimana strategi yang paling mudah menurutmu untuk mengetahui jumlah bulatan lego pada tingkat ke tujuh?, 3) soal dirancang agar siswa bernalar dengan menggunakan strategi yang dipilihnya, ini juga terlihat dari pertanyaan yang menanyakan strategi siswa, 4) soal dirancang agar siswa dapat merepresentasikan dan mengomunikasikan penalarannya, terlihat pada soal yang meminta siswa untuk menuliskan strateginya.

Selanjutnya, pada tahap expertreview, prototype I divalidasi oleh expert yang ahli di bidang PISA. Proses validasi dilakukan melalui email. Adapun komentar dan saran validator terhadap prototype I disajikan pada Tabel 1. 
DOI: https://doi.org/10.24127/ajpm.v10i2.3535

Tabel 1. Komentar dan saran validator terhadap prototype I

\begin{tabular}{|c|c|}
\hline Nama & Komentar dan Saran \\
\hline Validator 1 & $\begin{array}{l}\text { a. Perbaiki profil soal mengenai proses literasi, ganti } \\
\text { "menginterpretasi" menjadi "menerapkan": "Employ-This is } \\
\text { "intra-mathematical" work." } \\
\text { b. Perbaiki informasi soal mengenai tingkat ketujuh dari susunan } \\
\text { lego: "The seventh level will be underneath. Are the student building } \\
\text { this pyramid upside down? It seems a bit strange. Usually you } \\
\text { would build something like this from the bottom up. Can you make it } \\
\text { a bit more realistic? This is a nice setting for a question and by } \\
\text { asking for the number of "Dots" you avoid the question of the size } \\
\text { of the lego pieces. Just make the question more sensible." } \\
\text { c. Tambahkan keterangan bahwa lego tersusun secara padat:"I thought } \\
\text { that you meant the number of dots that can be seen. But you mean } \\
\text { the number on the level, whether seen or not. But how do we know } \\
\text { the pyramid is solid?" }\end{array}$ \\
\hline Validator 2 & $\begin{array}{l}\text { a. Perbaiki informasi soal mengenai tingkat ketujuh dari susunan lego: } \\
\text { "Do you mean the number of dots visible around the edge? Or the } \\
\text { total number of dots on the seventh layer? The question is not } \\
\text { clear." } \\
\text { b. Tambahkan keterangan bahwa lego tersusun secara padat: "Is the } \\
\text { shape hollow or solid? Cannot tell from the image." } \\
\text { c. Perbaiki pertanyaan dalam soal pada kalimat "strategi paling } \\
\text { mudah: "What could this mean? How can you decide what strategy } \\
\text { is "easiest"? }\end{array}$ \\
\hline
\end{tabular}

Kemudian, soal diujicobakan pada tahap one-to-one kepada teman sejawat berjumlah 2 orang dan siswa berjumlah
5 orang. Komentar dan saran teman sejawat terhadap prototype I dapat dilihat pada tabel 2 .

Tabel 2. Komentar dan saran teman sejawat terhadap prototype I

\begin{tabular}{ll}
\hline \multicolumn{1}{c}{ Nama } & Komentar dan Saran \\
\hline Teman & a. Hapus kata "menurutmu", jika ada kata "menurutmu" maka apapun \\
sejawat 1 & jawaban siswa tidak bisa disalahkan, karena strategi yang paling \\
& mudah untuk masing-masing siswa bisa berbeda-beda. \\
& b. Diperjelas, bahwa tingkat ketujuh adalah tingkat yang terbawah, \\
& bukan tingkat atas. Atau pengantarnya diganti: \\
& "Gambar di atas adalah piramida lego yang terdiri dari empat \\
& tingkat dan tingkat pertamanya berwarna merah putih." \\
Teman & a. Tambahkan penjelasan singkat mengenai lego mungkin ada \\
sejawat 2 & beberapa siswa yang tidak familiar dengan istilah 'lego'. \\
& b. Perbaiki pertanyaan dalam soal karena tidak jelas yang dimaksud \\
& tingkat ketujuh itu dari atas atau dari bawah. \\
& c. Perbaiki konteks dalam profil soal, lebih cocok sebagai konteks \\
& pribadi.
\end{tabular}


Soal yang diujicobakan kepada 5 orang siswa mendapatkan komentar siswa yang menanyakan "Tingkat ke tujuh itu yang mana, yang ke atas atau ke bawah?"

Setelah komentar dari expert, teman sejawat, dan siswa dianalisis, selanjutnya adalah menentukan keputusan untuk merevisi soal. Keputusan revisi antara lain menambahkan penjelasan dari lego, menambahkan penjelasan mengenai tingkat ke tujuh susunan lego, memperbaiki pertanyaan dalam soal, menghilangkan kata "menurutmu" dan "strategi paling mudah", mengganti proses matematika pada profil soal dari "menginterpretasi" menjadi "menerapkan", menetapkan konteks pada profil soal sebagai konteks pribadi, dan menambahkan keterangan bahwa lego disusun secara padat.

\section{UNIT 2. POLA LEGO}

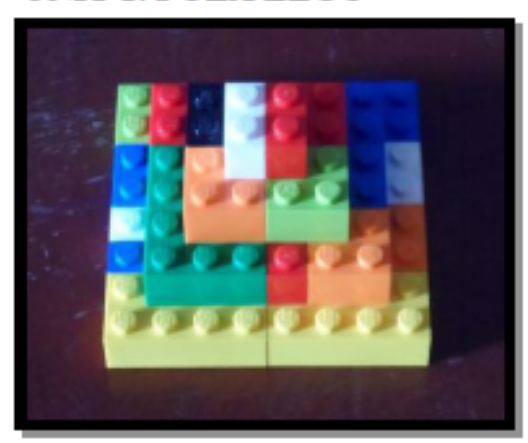

Lego adalah seperangkat mainan susun bangun yang terbuat dari plastik berbentuk persegi panjang, padat, dan bergerigi sehingga dapat disatukan dan dapat dibangun menjadi berbagai bentuk. Gambar di atas adalah piramida lego yang terdiri dari empat tingkat dan tingkat pertamanya adalah yang paling atas, yaitu lego yang berwarna merah putih.

\section{Pertanyaan 2:}

Jika lego tersebut ditambahkan kebawah hingga menjadi tujuh tingkat, berapa jumlah bulatan lego pada tingkat ketujuh? Tuliskan strategimu.

\section{Gambar 3. Prototype II}

Pada Gambar 3, terlihat soal yang sudah direvisi (prototype II) berdasarkan komentar dan saran pada tahap expert review dan one to one. Kemudian, prototype II diujicobakan kepada siswa pada tahap small group kepada 6 orang siswa. Siswa diberi waktu 80 menit untuk mengerjakan prototype II. Selama siswa mengerjakan soal, siswa diwawancarai dengan tujuan untuk mengetahui temuan, kesulitan, kendala, atau komentar siswa terhadap soal yang dikerjakan. Setelah siswa selesai mengerjakan soal, siswa diberi angket terbuka untuk mengetahui bagian yang dianggap sulit atau kurang dimengerti oleh siswa. Setelah menganalisis temuan dan komentar siswa pada tahap small group, ditentukan keputusan untuk merevisi soal atau tidak. Temuan pada saat small group yaitu siswa sudah mengerti maksud soal, gambar pada soal sudah jelas dan mendukung, sehingga keputusannya adalah soal tetap dipertahankan tanpa revisi. 
Pada tahap field test, protototype III diujicobakan kepada siswa 1 kelas yang berjumlah 12 orang. Pada tahap ini juga dilihat apakah siswa sudah mengerti maksud soal dan apakah soal memiliki efek potensial. Jawaban siswa pada tahap field test dapat dilihat pada Gambar 4.

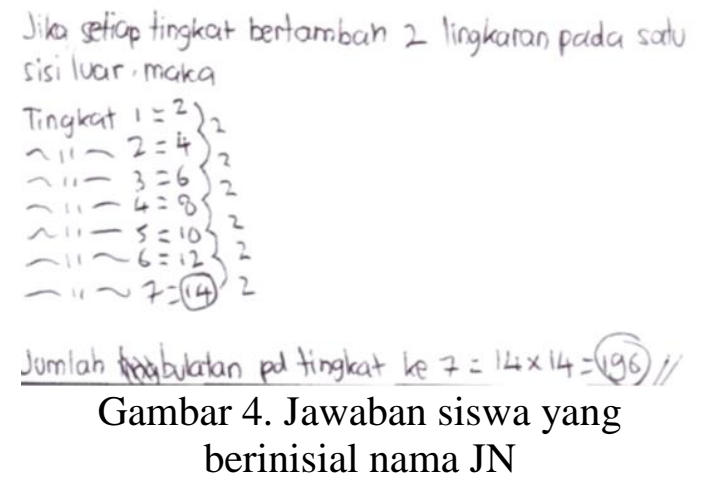

Pada Gambar 4, terlihat bahwa JN memenuni indikator kemampuan level 5 yaitu JN mampu memilih, membandingkan, menetapkan asumsi, hingga mengomunikasikan penalaran dalam bentuk simbol matematika. JN mampu menggunakan model yang ada pada gambar dan mengidentifikasi pola jumlah bulatan lego bahwa setiap tingkatan bertambah 2 dan kemudian dikuadratkan atau pola $(2 a)^{2}$, ini artinya JN mampu menginterpretasi, menganalisis, dan mengevaluasi permasalahan yang ada pada soal (Susilowati et al., 2017) sehingga JN dapat menentukan jawaban dengan tepat. Selain itu, JN mampu menetapkan asumsi dan mengkomunikasikan secara tertulis sesuai indikator kemampuan komunikasi tertulis (Suningsih \& Arnidha, 2017) bahwa jumlah bulatan lego pada tingkat ketujuh adalah $14 \mathrm{x}$ $14=196$.

Dilihat dari kemampuan berpikir tingkat tinggi sesuai taksonomi bloom, pada gambar 5 terlihat kemampuan menganalisis JN muncul, untuk menentukan jumlah lego pada tingkat ke tujuh, JN menganalisis pola pertambahan lego setiap tingkatnya. Kemudian, terlihat juga kemampuan mengevaluasi yaitu JN menghitung dan menentukan jumlah bulatan lego pada tingkat ke tujuh. Kemampuan mencipta juga terlihat pada jawaban JN, JN menuliskan pola pertambahan angka dari tingkat ke-1 sampai tingkat ke-7 sehingga terlihat jelas selisih angka dari tingkatan tersebut. Berdasarkan taksonomi bloom (Kemdikbud, 2017), kemampuan menganalisis, mengevaluasi, dan mencipta termasuk dalam kemampuan berpikir tingkat tinggi. Hal ini berarti efek potensial dari soal yang dikembangkan adalah mampu memunculkan kemampuan berpikir tingkat tinggi siswa (HOTS). Selain itu ada beberapa siswa lain yang menjawab benar dengan menggunakan strategi yang berbeda, seperti yang ditampilkan pada Gambar 5.

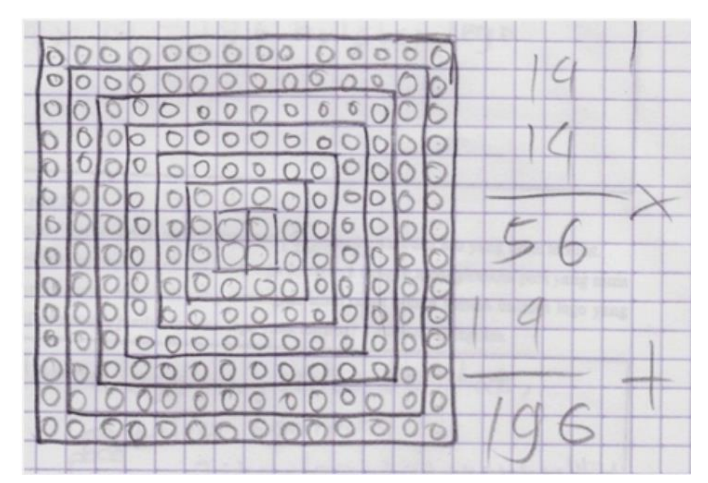

Gambar 5. Jawaban siswa yang berinisial nama ARU

Pada Gambar 5 terlihat bahwa ARU menentukan jumlah bulatan lego pada tingkatan ketujuh dengan cara menggambar susunan lego tersebut sehingga terlihat dari atas. Kemudian, ARU menghitung 14 x 14 sehingga mendapatkan bahwa jumlah bulatan lego pada tingkat ketujuh adalah 196.

Ada 50\% siswa mendapatkan skor maksimal pada soal ini. Temuan yang 
muncul dari soal ini adalah siswa mampu bernalar dan berargumentasi, serta menentukan strategi untuk menyelesaikan masalah, terlihat bahwa siswa mampu merancang sebuah strategi multi langkah untuk menjawab jumlah bulatan lego pada tingkat ke tujuh, siswa juga memiliki kemampuan matematisasi serta mengkomunikasikannya pada lembar jawaban berupa perhitungan angka maupun gambar. Hal ini menunjukkan juga bahwa siswa memiliki kemampuan menggunakan bahasa dan operasi simbolik. Ini sesuai dengan deskripsi kemampuan matematika level 5 dalam PISA (OECD, 2013).

Dilihat dari taksonomi bloom, terlihat kemampuan berpikir tingkat tinggi yang muncul dari jawaban ARU.
Terlihat kemampuan ARU dalam menganalisis gambar lego, padahal pada soal terlihat bahwa lego tidak tampak utuh, tapi ARU mampu menganalisis jumlah bulatan lego yang tidak terlihat. Selain itu, kemampuan mengevaluasi juga terlihat dari jawaban ARU, ditunjukkan dari ARU tidak hanya menghitung bulatan lego satu persatu, tapi ARU menghitung $14 \times 14$ untuk memastikan bahwa jumlah bulatan lego seluruhnya adalah 196. Kemudian, terlihat juga kemampuan mencipta dari jawaban ARU, ARU mampu menggambarkan secara detail gambar lego setiap tingkatannya.

Selain itu, beberapa siswa menjawab dengan strategi yang berbeda seperti pada gambar 6 .

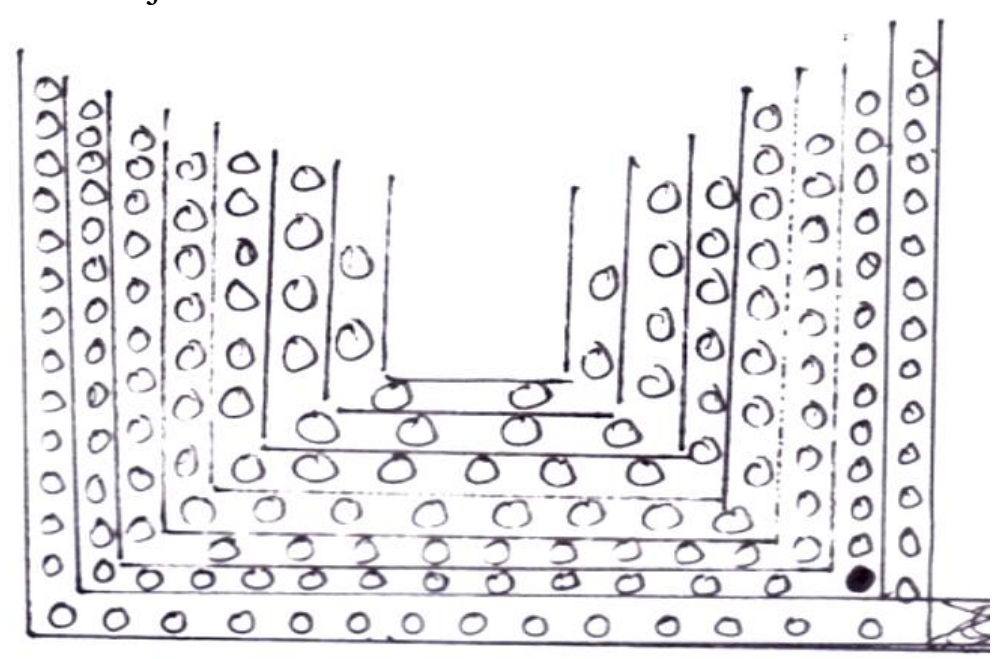

Gambar 6. Jawaban siswa yang berinisial nama AA

Pada gambar 6 terlihat AA menggambar bulatan lego hingga tingkat ke tujuh, AA telah menentukan dengan benar bahwa jumlah bulatan lego pada bagian pinggirnya berjumlah 14 dan 14, tapi AA tidak memberikan kesimpulan akhir mengenai jumlah bulatan lego pada tingkat ketujuh tersebut. AA mampu menganalisis, terlihat dari AA menggambarkan sampai tingkat ke tujuh dengan jumlah bulatan yang benar di bagian sisi depan, sisi kiri, dan sisi kanan, namun AA tidak mengevaluasi berapa jumlah bulatan lego pada tingkat ke tujuh tersebut sesuai dengan yang ditanyakan dalam soal. Namun secara umum AA sudah mengerti maksud soal dan dapat mengerjakan soal tersebut. Hal ini menunjukkan bahwa soal dapat digunakan dan artinya sudah praktis, sesuai dengan pendapat (Nieveen, 2010) yang menyatakan bahwa kriteria praktis adalah saat produk yang didesain dan 
dikembangkan dapat digunakan. Selain itu, soal yang dikembangkan sudah sesuai dengan kriteria konteks pribadi, yaitu mencakup aktivitas permainan dengan teman sebaya (OECD, 2018).

Dari uraian di atas, dapat dilihat bahwa soal yang dikembangkan sudah valid yang divalidasi pada tahap expert review dan one-to-one pada teman sejawat, kevalidan soal dilihat dari segi konten, konstruk, dan bahasa. Soal juga telah praktis yang diujicobakan pada tahap one to one pada siswa dan small group mengenai keterpakaian soal yang dikembangkan, serta soal memiliki efek potensial yang dilihat dari jawaban siswa pada tahap field-test.

Temuan dari penelitian ini yaitu, berdasarkan jawaban siswa pada tahap field-test, ditemukan bahwa soal matematika tipe PISA yang dikembangkan memiliki efek potensial yaitu memunculkan kemampuan berpikir tingkat tinggi siswa yang terdiri dari kemampuan menganalisis, mengevaluasi, dan mencipta. Hal ini terjadi karena soal yang dikembangkan sesuai dengan indikator soal level 5 pada framework PISA yang deskriptornya mencakup kemampuan berpikir yang terdiri dari siswa dapat mengembangkan dan bekerja dengan model dan situasi kompleks, siswa dapat mengidentifikasi kendala serta menetapkan asumsi, siswa dapat memilih, membandingkan, dan mengevaluasi strategi pemecahan masalah yang sesuai untuk menyelesaikan masalah kompleks yang terkait dengan model, siswa dapat bekerja secara strategis menggunakan keterampilan berpikir dan penalaran, representasi terkait yang sesuai, karakterisasi formal dan simbol, dan wawasan yang berkaitan dengan situasi, serta siswa dapat merefleksikan tindakan dan merumuskan serta mengkomunikasikan interpretasi dan penalaran (OECD, 2018). Hal ini sejalan dengan penelitian terdahulu oleh Putri \& Zulkardi (2020), Rawani Putri, \& Hapizah (2019), Yansen, dkk (2019) yang hasil penelitiannya menunjukkan bahwa soal matematika tipe PISA yang dikembangkan memiliki efek potensial yaitu memunculkan kemampuan berpikir tingkat tinggi siswa. Dampak dari penelitian ini adalah dihasilkan perbendaharaan soal matematika tipe PISA level 5 yang dapat digunakan oleh guru sebagai latihan siswa. Selain itu, terlihat kemampuan berpikir tingkat tinggi siswa saat mengerjakan soal matematika tipe PISA yang dikembangkan, sehingga guru dapat mengeksplorasi kemampuan tersebut agar dapat ditingkatkan.

\section{KESIMPULAN DAN SARAN}

Berdasarkan proses pengembangan soal, dihasilkan soal matematika model PISA level 5 dengan konteks pribadi yang valid dan praktis secara kualitatif. Soal dinyatakan valid secara konten karena sudah sesuai dengan framework PISA, sesuai dengan kriteria soal PISA level 5 dan kriteria konteks pribadi, soal sudah valid dari segi konstruk karena sudah sesuai dengan materi yang ada dalam kurikulum 2013 di kelas VIII, dan soal juga sudah valid secara bahasa karena sudah sesuai dengan PUEBI dan tidak menimbulkan penafsiran yang ambigu atau penafsiran ganda. Soal juga dinyatakan praktis yang menunjukkan bahwa soal bisa digunakan oleh siswa, siswa mengerti maksud soal, dan soal memunculkan kemampuan berpikir tingkat tinggi siswa.

Saran dari penelitian ini yaitu sebaiknya dikembangkan juga soal matematika tipe PISA level 6 dan menggunakan konteks yang lain selain konteks pribadi. 


\section{DAFTAR PUSTAKA}

Baka, N. A., Laksana, D. N. L., \& Dhiu, K. D. (2019). Konten dan Konteks Budaya Lokal Ngada sebagai Bahan Ajar Tematik di Sekolah Dasar. Journal of Education Technology. https://doi.org/10.23887/jet.v2i2.1 6181

Bakker, A. (2019). Design Research in Education: A Practical Guide for Early Career Researhers. Routledge.

Effendi, R. (2017). Konsep Revisi Taksonomi bloom dan Implementasinya pada Pelajaran Matematika SMP. JIPMat. https://doi.org/10.26877/jipmat.v2 i1.1483

Fauziyah, H. N. (2020). Analisis SoalSoal Buku Ajar Matematika Kelas VII Ditinjau dari Revisi Taksonomi bloom. In Skripsi. Universitas Muhammadiyah Surakarta.

http://eprints.ums.ac.id/82847/12/ Naskah Publikasi.pdf

Gustiningsi, T. (2015). Pengembangan Soal Pengayaan Model PISA Level 4 Kelas VII SMP. Jurnal Pendidikan Matematika JPM RAFA, 2(2), 198-213. http://jurnal.radenfatah.ac.id/index .php/jpmrafa/article/view/1248

Gustiningsi, T., \& Utari, R. S. (2020). Developing of Higher Order Thinking Skill (HOTS) Mathematical Problems With Cartesian Coordinate Material. 4th Sriwijaya University Learning and Education, 513, 561-566. https://www.atlantispress.com/article/125950370.pdf

Johar, R. (2012). Domain Soal PISA untuk Literasi Matematika. Jurnal Peluang, $\quad$ (1), 30-41. http://www.jurnal.unsyiah.ac.id/p eluang/article/view/1296

Kemendikbud. (2017). Modul Penyusunan Soal Higher Order Thinking Skill ( HOTS). Direktorat Pembinaan SMA, Direktorat Jendarl Pendidikan Dasar Dan Menengah, Departemen Pendidikan Dan Kebudayaan. https://doi.org/10.1017/CBO9781 107415324.004

Munayati, Z., Zulkardi, Z., \& Santoso, B. (2015). Kajian soal buku teks matematika kelas $\mathrm{X}$ kurikulum 2013 menggunakan framework PISA. Jurnal Pendidikan Matematika, 9(2).

Nieveen, N., Van den Akker, J., Gravemeijer, K., \& McKenney, S. (2006). Educational Design Research. In Educational Design Research. Routledge. https://doi.org/10.4324/97802030 88364

OECD. (2013). PISA 2012 Assessment and Analytical Framework: Mathematics, Reading, Science, Problem Solving and Financial Literacy. In OECD Publishing. https://doi.org/http://dx.doi.org/10 .1787/9789264190511-en

OECD. (2016). PISA 2015 Results. In OECD Publishing. https://doi.org/10.1787/97892642 66490-en

OECD. (2018). PISA 2021 Mathematics Framework Publishing.

(Draft).OECD

OECD. (2019a). PISA 2018 insights and interpretations. OECD Publishing.

OECD. (2019b). PISA 2018 Mathematics Framework. OECD Publishing. https://doi.org/10.1787/13c8a22cen 
Oktiningrum, W., Zulkardi, \& Hartono, Y. (2016). Developing PISA-Like Mathematics Task with Indonesia Natural and Cultural Heritage as Context to Assess Students' Mathematical Literacy. Journal on Mathematics Education, 7(1), $1-8$.

https://doi.org/10.22342/jme.7.1.2 812.1-8

Putra, Y. Y., Zulkardi, Z., \& Hartono, Y. (2016). Pengembangan Soal Matematika Model PISA Level 4, 5, 6 Menggunakan Konteks Lampung. Kreano, Jurnal Matematika Kreatif-Inovatif. https://doi.org/10.15294/kreano.v $7 \mathrm{i} 1.4832$

Putri, R. I. I., \& Zulkardi. (2020). Designing PISA-like Mathematics Task Using Asian Games Context. Journal on Mathematics Education, 11(1), 135-144. https://doi.org/10.22342/jme.11.1. 9786.135-144

Rawani, D., Putri, R. I. I., \& Hapizah. (2019). PISA-like mathematics problems: Using taekwondo context of Asian games. Journal on Mathematics Education, 10(2), 277-288.

https://doi.org/10.22342/jme.10.2. 5243.277-288

Setiawan, H., Diah, N., Lestari, S., Studi, P., Matematika, P., Matematika, L., \& Tingkat, K. B. (2014). Soal Matematika dalam PISA Kaitannya dengan Literasi Matematika dan Kemampuan Berpikir Tingkat Tinggi. Prosiding Seminar Nasional Matematika, 1(1).

Suningsih, A., \& Arnidha, Y. (2017). Komunikasi Matematis Siswa Tunarungu melalui Model Pembelajaran Think Pair Share. Jurnal Aksioma, 6(3), 375-384.
https://doi.org/DOI:

http://dx.doi.org/10.24127/ajpm.v $6 \mathrm{i} 3.1127$

Susilowati, Sajidan, \& Ramli, M. (2017). Analisis Keterampilan Berpikir Kritis Siswa Madrasah Aliyah Negeri di Kabupaten Magetan. Seminar Nasional Pendidikan Sains 21, 223-231. http://www.jurnal.fkip.uns.ac.id/in dex.php/snps/article/viewFile/114 $17 / 8102$

Tessmer, M. (1993). Planning and conducting formative evaluations: Improving the quality of education and training. In Planning and Conducting Formative Evaluations. Kogan Page.

Widodo, T., \& Kadarwati, S. (2013). Higher Order Thinking Berbasis Pemecahan Masalah untuk Meningkatkan Hasil Belajar Berorientasi Pembentukan Karakter Siswa. Jurnal Cakrawala Pendidikan, 32(1), 161-171.

https://doi.org/10.21831/cp.v5i1.1 269

Yansen, D., Putri, R. I. I., Zulkardi, \& Fatimah, S. (2019). Developing PISA-Like Mathematics Problems on Uncertainty and Data using Asian Games Football Fontext. Journal on Mathematics Education, 10(1), 37-46. https://doi.org/10.22342/jme.10.1. 5249.37-46

Zulkardi. (2002). Developing a Learning Envorinment on Realistic Mathematics Education for Indonesian Students Teachers. Thesis. University of Twente. Enschede:Printpartners Ipskamp. 